\title{
The Experimental Design of App Games to Bridge the Gap Between Two Generations
}

\author{
Hsing-yu Hou, TransWorld University
}

\begin{abstract}
The increasingly ageing population is an important issue for family relationships. If the human-device interface is well designed, older citizens can manage icons more easily than typing on a keyboard. The authors use the design of experiment method to evaluate the effect of App games. There are $2 * 2 * 2=8$ combinations in the experiment. The three factors are image size, touch guidelines and degree of complication. The independent variables are gender, age, technology sensitivity and the attitude to risk. The dependent variable is the game score. It is proven that simplicity, clear guidelines and small screen result in better performance. The elderly like big screens but Apps do bot provide this. These results allow App designers to direct development. More attention to the needs of the elderly during the shooting process might also improve interaction between the elderly and youths.
\end{abstract}

Keywords : Design of Experiment, App Game, Generation Interaction

\section{INTRODUCTION}

In eastern culture, filial piety is very important. It requires the demonstration of respect and love to aged parents and seniors. Changing social mores, the embryonic state of the social safety net and the demographic "time bomb" of a fast-ageing population have made officials keener than ever to promote filial piety. Teaching parents how to use the Internet is a new way to bridge the gap between the elderly and youths. Thanks to Applorer, players only need to visit Google Play, click on the Games tab and an entire list of the most popular App games is presented. Of the 162,000 available gaming Apps, the list is dominated by Angry Birds. This research determines how to teach the elderly how to play Angry Birds. A design of experiment for App games is then undertaken. In the process of the experiment, the authors record the players' attitude and collect the feedback to the App design. If the human-device interface is well designed, the elderly can use icons more easily than they can type on a keyboard.

\section{LITERATURE REVIEW}

Good interface design increases the motivation to use a product. In order to persuade the elder to play App games, the design factors must be considered.

\section{A. Metro App Design Principles}

For too many years, users have been forced to think in the way an application requires. Software is formalistic, with strict rules and logic, but human behavior, by nature, is less defined and not always based on logic. Historically, software has not taken the needs of end users into sufficient consideration. This will change, as younger generations are much less forgiving of poor software design. There is a need to design applications that are fluid in both their graphic and local design.

Dino Esposito (2012) stated that Metro-style apps leverage several features specific to the new Microsoft operating system. They are touch-enabled (but not limited to touch) and are displayed in a single plain borderless window that is devoid of adornment. They adapt to the screen's size and shape and can offer a fluid rendering experience, as the content adjusts smoothly and intelligently to the layout of the screen. Finally, these apps integrate with the surrounding environment via the app bar, which is a hidden top menu. Live tiles, are a smart replacement for desktop icons and charms and quick buttons allow the application to interact with other apps, through well-known contracts.

Seven characteristics that make these apps popular are:

1). Design for touch and intuitive interaction.

2). Be responsive to user interaction and ready for whatever should come next.

3). Reduce redundancy.

4). Use a consistent UI model.

5). Use native tools.

6). Make your app work with others.

7). Connect to the cloud so that your users can stay connected to each other.

\section{B. Design of Experiment}

Wikipedia (2012) states that design of experiments (DOE) or experimental design is the design of any 
information-gathering exercises where variation is present, whether under the full control of the experimenter or not. However, in statistics, these terms are usually used for controlled experiments. Formal planned experimentation is often used to evaluate physical objects, chemical formulations, structures, components and materials. Other types of study and their design are discussed in articles on opinion polls and statistical surveys (which are a type of observational study), natural experiments and quasi-experiments (for example, quasi-experimental design). Design of experiment is a discipline that has very broad applications across all the natural and social sciences and engineering.

A methodology for the design of experiments was proposed by Ronald A. Fisher, in his innovative books: "The Arrangement of Field Experiments" (1926) and The Design of Experiments (1935). Much of his pioneering work dealt with agricultural applications of statistical methods. As a mundane example, he described how to test the hypothesis that someone could distinguish by flavour alone whether milk or the tea was placed in the cup first. These methods have been broadly adapted in the physical and social sciences and continue to be used in agricultural engineering.

\section{METHOD}

In recent years iPhones and iPads have become more popular than PC's, for playing games. Rovio entertainment Ltd developed and researched many games, such as Amazing Alex, Angry Birds and Bounce Evolution. In order to allow the elderly to use a convenient interface in the experimental process, the authors use an iPad as the playing tool. The details are shown below:

\section{A. App Games (Angry Birds)}

The survival of the Angry Birds is at stake. There must be revenge on the green pigs who have stolen the Birds' eggs. The unique destructive powers of the Angry Birds are used to lay waste to the pigs' fortified castles. Angry Birds features hours of gameplay and challenging physics-based castle demolition and allows repeated replay. Logic, skill and brute force are used to crush the enemy.

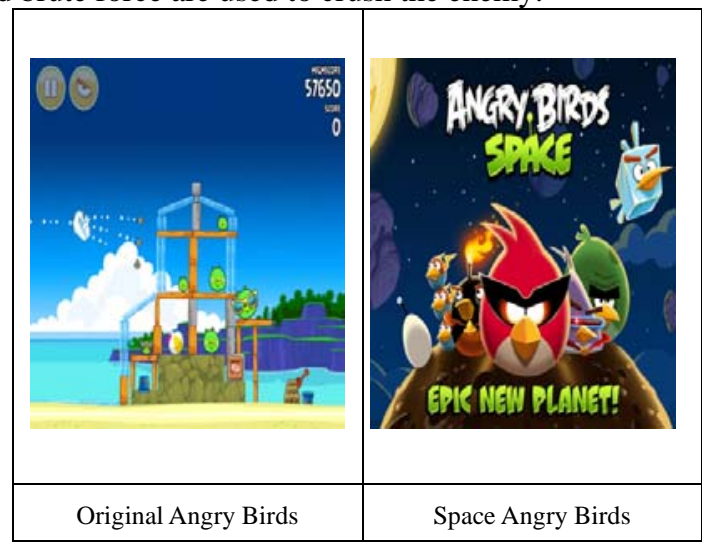

Figure I Angry Birds Situations

\section{B. Factors}

The design of App games allows users to use big or small screens. In the game situation, the original Angry Bird lacks guidelines but space Angry Bird has this function. There are also several levels that allow players to test their skill and logic. Therefore, for the DOE, the three factors are visual size, touch guidelines and the degree of complication.

\section{Combinations}

For the three factors, there are $2 * 2 * 2=8$ combinations in this experiment. The three factors are coded as below: visual size big (1) and small (2); without guidelines (1) and with guidelines (2); simple level (1) and complicated level (2).

Table I DOE Combinations

\begin{tabular}{|c|c|c|c|}
\hline \multicolumn{4}{|c|}{ Table I DOE Combinations } \\
\hline 1 & visual size & guideline & complicated degree \\
\hline 2 & 1 & 1 & 1 \\
\hline 3 & 1 & 1 & 2 \\
\hline 4 & 1 & 2 & 1 \\
\hline 5 & 1 & 2 & 1 \\
\hline 6 & 2 & 1 & 2 \\
\hline 7 & 2 & 1 & 1 \\
\hline 8 & 2 & 2 & 2 \\
\hline
\end{tabular}

D. Participants

The experiment has ten participants (male: 5, female: 5; elderly: 5 youth: 5 ). The age of the older participants is more than 50 years old and the youth participants are 20-40 years old. It is believed that the sensitivity to technology is greater in youth than in the elderly. After eight runs with the App games, the authors determine the attitude to risk and games feedback. The independent variables are gender, age, sensitivity to technology and attitude to risk and the dependent variable is the game score. The App game calculates the final scores automatically, depending on how successfully the player shoots.

\section{E. Procedures}

Step 1 Select the situation

Step 2 Teach the participant how to use the iPad

Step 3 State the rules of the App games

Step 4 Let the player try once

Step 5 Repeat the experiment eight times

Step 6 Record the scores

Step7 Determine the attitude to risk and collect the users' 
feedback

\section{RESULTS}

The game situations were coded to $\mathrm{A}$, the degree of complication, to $\mathrm{B}$ and the visual size to $\mathrm{C}$.

The data shows that if the game has guidelines, is simple and the visual size is small but complete, the final scores are better.

Table II Estimated Effects and Coefficients for Score

\begin{tabular}{|c|c|c|}
\hline Term & Effect & Coefficient \\
\hline Constant & & 25413 \\
\hline A & 3866 & 1933 \\
\hline B & -5903 & -2952 \\
\hline C & 3767 & 1884 \\
\hline A*B & 3096 & 1548 \\
\hline A*C & 2004 & 1002 \\
\hline B*C & -2457 & -1229 \\
\hline A*B*C & -2938 & -1469 \\
\hline
\end{tabular}

The second stage correlation coefficient analyses are shown below:

\begin{tabular}{|c|c|c|c|c|}
\multicolumn{5}{c}{ Table III Correlation Coefficient } \\
\hline & AGE & GENDER & TECH & RISK \\
\hline Score & -.324 & .201 & .365 & .098 \\
\hline
\end{tabular}

The youth are coded as 1 and the elderly as 2 . Male is 1 and female is 2. Infrequent use of technology is 1 and frequent is 2 . Aversion to risk is 1 and an affinity with risk is 2 .

The findings show that youth perform better, because they are more sensitive to technology and have an affinity with risk. Females score better, because three are youths.

\section{DISCUSSION}

It is proven that the simple games, process with guidelines and a small screen produce better performance. The elderly like big screens but Apps cannot show the complete situation. These results allow App designers to direct their development. Taking care during the shooting process can improve interaction between the elderly and youth. In particular for complicated levels, youths can teach the elderly how to use linking to hit many objects at one time.

It is observed that not only youths have an affinity with risk, but also some of the elderly, after eight repetitions of the experiment. The feedback from the elderly indicates joy and excitement. They want to play again and are interested in the tool. Because it is thought that high technology builds a wall between the elderly and youth, most older citizens are afraid of playing with computers. Fortunately, the elderly prefer the iPad icons of amusing App games. Youths can teach their parents on the Internet. If App designers increase the screen size and add more human functions for the elderly, communication between the elderly and youth may be improved.

\section{CONCLUSIONS}

Ageing populations are growing so family relationships are changing. If the human-device interface is well designed, the elderly can use touch icons more easily than typing on a keyboard. The authors use a design of experiment to determine that simpler games, with guidelines and a small screen produce better performance. High technology is neither terrifying nor divisive of generations. If App designers can improve the size of iPads and add more human functions for the elderly, parent-child interaction may be increased and the gap between the elderly and youth can be bridged. Continued research may lead to the design of different types of App games and motivate family discussion by encouraging cooperation between generations.

\section{REFERENCES}

[1] Esposito, D. (2012), "Metro App Design Principles", InformationWeek, Vol. 1338, pp34.

[2] Fisher, R.A. (1971) The Design of Experiments, 9th Edition, Macmillan

[3] http://en.wikipedia.org/wiki/Design_of_experiments

[4] http://www.rovio.com/en/our-work/games/view/1/angry-birds

[5] http://www.todayonline.com/Technology/EDC120815-0000012/Ga me-discovery-made-easy-with-Applorer

[6] http://www.todayonline.com/World/China/EDC120817-0000029/Te ach-parents-how-to-use-the-Internet

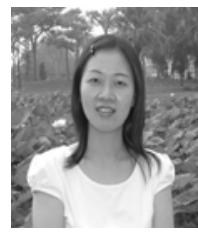

Hsing-Yu Hou is a Ph.D at the Department of Industrial Engineering and Management, National Yunlin University of Science and Technology in Taiwan. She is also an assistant professor at the department of Business Administration, Transworld University. Hou's research interests include E-Learning, ergonomics and management information systems. She has computer licenses such as advanced software application certification, $\mathrm{IC}^{3}$.international certifications, and Enterprise Resource Planning application certifications. 